\title{
Molecular characterization of vembur sheep (Ovis aries) of south India based on microsatellites
}

S. Pramod, P. Kumarasamy*, A. Rosalyn Mary Chandra, P. Sridevi and P. S. Rahumathulla

Department of Animal Genetics and Breeding, Madras Veterinary College

Tamilnadu Veterinary and Animal Sciences University, Chennai - 600 007, India

pksamy2000@gmail.com*

Abstract: The Vembur sheep is a mutton breed, adapted to semi arid habitat and distributed in and around Thoothukudi, Virudhunagar and Tirunelveli districts of Tamilnadu, India. Microsatellite characterization yielded a total of 147 alleles in the sampled population for 25 marker loci under investigation, with a mean of $5.88 \pm$ 0.29 alleles per locus. Number of alleles observed on each locus varied between two and nine. The effective number of alleles observed with a mean of $4.0950 \pm 0.23$ alleles per locus. The mean PIC value was $0.6905 \pm 0.02$. The frequency of majority of the loci returned highly significant chi-square values suggesting departure from $\mathrm{HWE}$. The observed heterozygosity $(\mathrm{Ho})$ values varied between 0.1333 and 1.0000 , while the expected $(\mathrm{He})$ values ranged from 0.4847 to 0.8537 . The mean values were $0.5202 \pm 0.04$ and $0.7339 \pm 0.02$ respectively. $F_{I S}$ estimates were negative for three loci indicating more heterozygous nature of the population. The mean value observed was $0.2954 \pm 0.31$.

Keywords: Vembur sheep, microsatellites, PIC, $\mathrm{F}_{\mathrm{IS}}$ India. Introduction

Sheep were probably first domesticated in the Fertile Crescent, $\sim 8000$ to 9000 years ago. Archaeological information revealed two independent areas of sheep domestication in Turkey- the upper Euphrates valley in eastern Turkey, and central Anatolia (Peters et al., 1999). It was suggested that, three species of wild sheep viz., the urial, Ovis vignei, the argali, Ovis ammon; and the Eurasian mouflon, Ovis musinom/orientalis were ancestors of domestic sheep. The Indian Council for Agricultural Research (ICAR) estimates the existence of 40 sheep breeds in India. The strategy employed to classify a large number of sheep and goat breeds in India was based on identifiable morphological characteristics that were distinct from other populations in the vicinity, particularly those with a local name (Acharya, 1982; Shrestha, 2005).

The Vembur sheep (Ganesakale \& Rathnasabapathy, 1973; Acharya, 1982) is distributed among the three southern districts of Tamilnadu, namely Thoothukudi, Virudhunagar and Tirunelveli (Fig. 1). The population estimated in 1977 was $0.251 \mathrm{~m}$ (Acharya, 1982). The present population of the breed assessed by SEVA, a non-governmental organization working for conservation of indigenous breeds was around 2,000. Cross breeding, change in land use pattern, availability of alternate employment and subsequent reduction in the number of herdsmen are all suggested as reasons for severe reduction in population. Genetic characterization of Vembur sheep was performed using 25 microsatellite markers recommended by Food and Agricultural Organization for diversity studies on ovines (FAO, 2004)

\section{Material and methods}

Blood samples were collected from 50 Vembur sheep (Fig. 2), unrelated by ancestry from the breeding tract and genomic DNA was isolated by phenol-chloroform method (Sambrook et al., 1989).

\section{Amplification and genotyping}

The stock DNA was diluted in sterile ultra filtered water so as to contain $20-50 \mathrm{ng}$ of genomic (material) DNA per microlitre. The primers were diluted to $10 \mathrm{pM}$ in ultra filtered water. The reaction mixture consisted of Master mix (Bangalore Genei) 10 $\mu \mathrm{l}$; genomic DNA $3 \mu \mathrm{l}$; $0.8 \mu \mathrm{l}$ of each forward and reverse primer $(5 \mathrm{pM})$ and 5.4 $\mu \mathrm{l}$ of ultra filtered water in a reaction volume of $20 \mu \mathrm{l}$. The loci BM8125, CSSM31, HUJ616, OarCP20, OarFCB128, OarFCB48, OarHH41, OarJMP8, RM4, TGLA137 and TGLA377 were amplified by PCR programme with respective annealing temperatures (Bishop et al., 1995) for 35 cycles. The loci BM1314, BM6506, BM6526, BM757, BM827, CSSM47, OarAE129, OarJMP29, OarCP34, OarFCB20, OarHH35, OarHH47, OarHH64 and OarVH72 were amplified with a 'touch down' programme suggested by FAO (2004), with an additional extension step of $72^{\circ} \mathrm{C}$ for $45 \mathrm{~S}$ for 25 cycles at $48^{\circ} \mathrm{C}$. The PCR products were separated on a $6 \%$ denaturing polyacrylamide gel and silver-stained using a simplified method (Lujiang Qu et al., 2005). The silver-stained gels were analysed by Diversity Database software (Bio-Rad, USA) for scoring the alleles. The product sizes were determined with the help of $10 \mathrm{bp}$ DNA ladder (Invitrogen, USA) as a standard marker. The genotypes were scored based on the presence of a single band (homozygotes) or double bands (heterozygotes) in the gel.

\section{Molecular genetic analysis}

Allele frequencies, effective number of alleles, test of Hardy-Weinberg equilibrium (HWE), observed and expected heterozygosity and F-statistics were calculated using the Popgene version 1.31 (Yeh et al.,1999). The polymorphism information content (PIC) for each marker was determined separately for the groups of animals using the following equation:

$$
P I C=1-\sum_{i=1}^{n} p_{i}^{2}-2\left[\sum_{i=1}^{n-1} \sum_{j=i+1}^{n} p_{i}^{2} p_{j}^{2}\right]
$$

where $p_{i}$ is the frequency of the th allele, and $n$ is the number of alleles (Botstein et al., 1980).

\section{Results and discussion}

Number of observed alleles

A total of 147 alleles were delineated from the sampled population with a mean of $5.88 \pm 0.29$ alleles per locus. Number of alleles observed on each locus varied between two (OarHH47) and nine (HUJ616). Among
Research article

(c)Indian Society for Education and Environment (iSee)
"Vembur sheep: molecular characterization" http://www.indjst.org
Pramod et al. Indian J.Sci.Technol. 
other Tamilnadu breeds, 125 alleles were reported for Nilagiri (Girish et al., 2007) in 25 loci with a mean of 5 per locus and 143 alleles with a mean of $6.88 \pm 0.85$ in 27 loci for Coimbatore sheep (Kumarasamy et al., 2009) which were lower than the findings of the present study. Allele numbers in Madras Red and Mecheri (Prema et al., 2008; Selvam et al., 2009), were 189 and 195 respectively which were higher than that for Vembur sheep.

In Jalauni sheep (Arora et al., 2008) 148 alleles were observed over 25 loci, with a mean of 5.92 which is comparable to Vembur sheep. In Garole sheep, the observed number of alleles reported was 6.2 (Sodhi et al., 2003), which is higher than that of the present study. In Nali and Chokla sheep breeds (carpet wool breeds of Northwestern India), a total of 138 and 133 alleles respectively were reported. The number of observed allele ranged from 3 to 10 in Nali and 2 to 8 in Chokla with the respective means of 5.52 and 5.32 alleles (Sodhi et al., 2005), which is similar to the observation of the present study.

In Magra breed of sheep, another carpet wool breed of Northwestern India, the number of observed alleles ranged from 3 to 10 with a mean of 5.7 (Arora \& Bhatia, 2006). In exotic sheep breeds, a wide range of number of observed alleles were reported (2 to 4, GutierrezEspelata et al., 2000 and 7 to 28, Pariset et al., 2003).

\section{Effective number of alleles}

The effective number of alleles in Vembur sheep over 25 loci ranged from $1.9406(\mathrm{OarHH} 47)$ to 6.8368 (HUJ616) with a mean of $4.095 \pm 0.23$ alleles per locus (Table 1). The effective number of alleles at each locus provides

information

predominant

alleles. Among

other Indian

breeds, values

lower than that of Vembur sheep were observed by many authors, 3.7 in Jalauni sheep (Arora et al., 2008); 2.18 in Nilagiri sheep (Girish et al., 2007); 3.34 in Nali sheep (Sodhi et al., 2005); 3.27 in Chokla sheep (Sodhi et al., 2005); 3.64 in Muzzafarnagri breed (Arora \& Bhatia, 2004). Madras Red and Mecheri breeds

Research article

CIndian Society for Education and Environment (iSee)

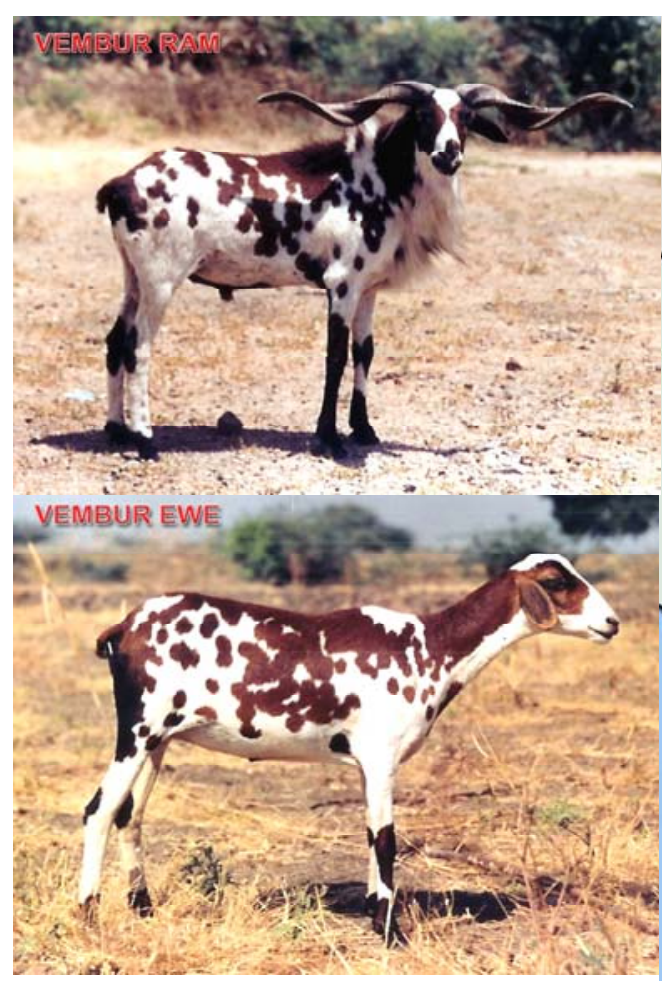

Fig. 2. Photographs of Vembur sheep
(Selvam et al., 2009; Prema et al., 2008) and Coimbatore sheep (4.93, Kumarasamy, et al., 2009) had higher mean values than that of Vembur sheep.

Polymorphism information content

PIC values for Vembur sheep (Table 1) ranged from 0.3712 (OarHH47) to 0.8360 (HUJ616) with a mean of $0.6905 \pm 0.02$. 24 out 25 loci (96 per cent) had PIC values greater than 0.5 which prove their utility for genetic diversity studies. OarHH47 was found to be reasonably informative $(0.50>P I C>0.25)$. Among the Indian sheep breeds, the PIC values ranged from 0.533 to 0.808 in Muzzafarnagri sheep (Arora \& Bhatia, 2004) and 0.210 to 0.831 and 0.346 to 0.768 in Nali and Chokla sheep breeds respectively (Sodhi et al., 2005), 0.347 to 0.849 in Magra sheep (Arora \& Bhatia, 2006), 0.4587 to 0.8277 in Nilagiri sheep, and 0.24 to 0.82 in Jalauni sheep (Arora et al., 2008) using ovine-specific microsatellite markers.

\section{Hardy-Weinberg equilibrium}

The results of the $x^{2}$ test of goodness of fit (Table 1) proved that majority of the loci under investigation (19 out of 25) returned highly significant chi square values suggesting departure from HWE. The loci OarHH47,

OarJMP29 and TGLA377 revealed statistically significant departure from HWE, while the loci BM1314, OarCP34 and OarFCB20 were observed to be in HWE. The observations from Vembur sheep in this regard were in agreement with the findings of Madras Red and Mecheri (Prema et al., 2008; Selvam et al., 2009) and Coimbatore breeds (Kumarasamy et al., 2009). The departure from HWE in majority of the loci could be attributed to shrinkage in population size and selection

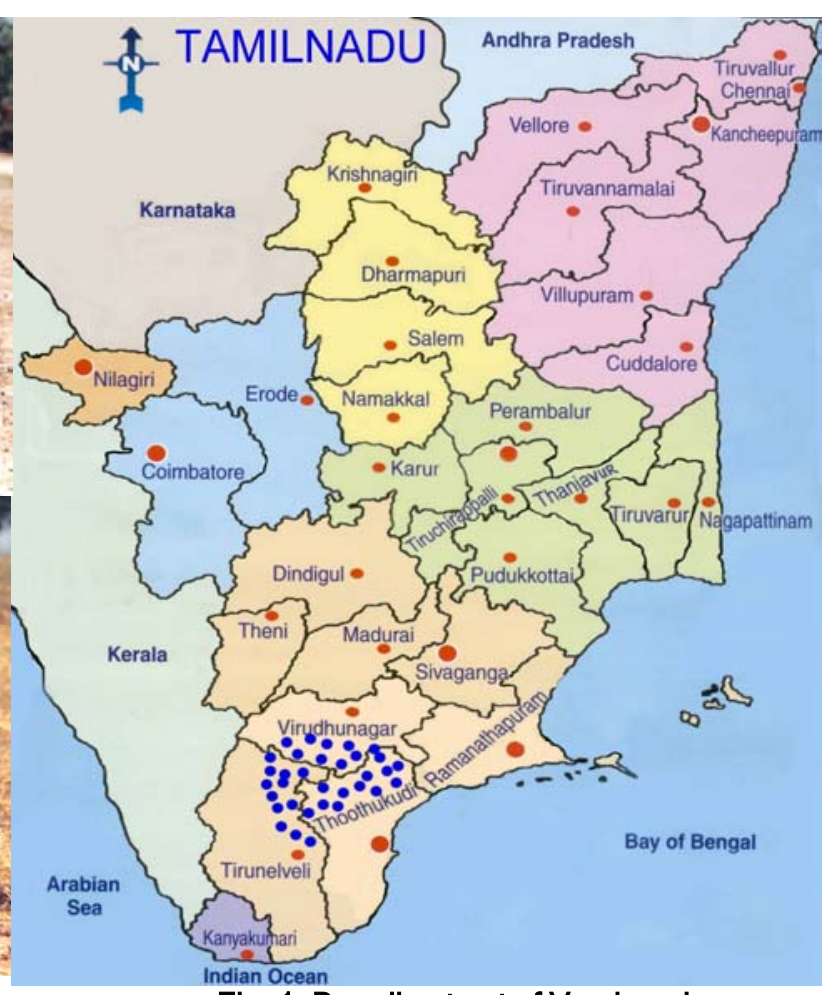

Fig. 1. Breeding tract of Vembur sheep
"Vembur sheep: molecular characterization" http://www.indjst.org
Pramod et al. Indian J.Sci.Technol. 
Table 1. Number of observed and effective alleles, size of alleles, polymorphism information content, observed and expected heterozygosity at 25 microsatellite loci in Vembur sheep

\begin{tabular}{|c|c|c|c|c|c|c|c|c|}
\hline \multirow[b]{2}{*}{ locus } & \multirow{2}{*}{$\begin{array}{l}\text { Obser } \\
\text {-ved } \\
\text { allele } \\
\text { s } \\
\end{array}$} & \multirow{2}{*}{$\begin{array}{l}\text { Effective } \\
\text { Number } \\
\text { of alleles }\end{array}$} & \multirow{2}{*}{$\begin{array}{l}\text { Allele } \\
\text { size } \\
\text { (bp) }\end{array}$} & \multirow[b]{2}{*}{ PIC } & \multirow{2}{*}{$\begin{array}{c}\text { Hardy- } \\
\text { Weinberg } \\
\text { equilibrium } \\
\text { ( } x^{2} \text { value ) }\end{array}$} & \multicolumn{2}{|c|}{ Heterozygosity } & \multirow{2}{*}{$\begin{array}{c}\text { Within } \\
\text { population } \\
\text { inbreeding } \\
\text { estimate }\left(F_{I S}\right)\end{array}$} \\
\hline & & & & & & Observed & Expected & \\
\hline BM1314 & 8 & 6.0157 & $160-186$ & 0.8129 & $21.85^{\mathrm{NS}}$ & 0.7500 & 0.8338 & 0.1005 \\
\hline BM6506 & 6 & 4.5453 & $180-200$ & 0.7474 & $93.32^{* *}$ & 0.3617 & 0.7800 & 0.5363 \\
\hline BM6526 & 6 & 4.3513 & 154-172 & 0.7382 & $44.86^{\star \star}$ & 0.5625 & 0.7702 & 0.2697 \\
\hline BM757 & 7 & 5.0141 & 172-196 & 0.7717 & $205.20^{* *}$ & 0.3750 & 0.8006 & 0.5316 \\
\hline BM8125 & 6 & 2.6982 & $110-124$ & 0.5732 & $186.38^{* *}$ & 0.1333 & 0.6294 & 0.7882 \\
\hline BM827 & 4 & 2.5538 & $208-230$ & 0.5284 & $63.87^{* *}$ & 0.8936 & 0.6084 & -0.4687 \\
\hline CSSM31 & 5 & 4.1581 & $148-158$ & 0.7202 & $45.96^{* \star}$ & 0.4000 & 0.7595 & 0.4733 \\
\hline CSSM47 & 6 & 2.6282 & $132-162$ & 0.5480 & $36.97^{\star \star}$ & 0.2766 & 0.6195 & 0.5535 \\
\hline HUJ616 & 9 & 6.8368 & $112-128$ & 0.8360 & $80.89^{* *}$ & 0.7609 & 0.8537 & 0.1088 \\
\hline OarAE129 & 8 & 4.3855 & $132-158$ & 0.7325 & $76.63^{\star \star}$ & 0.4565 & 0.7720 & 0.4086 \\
\hline OarCP20 & 5 & 3.4522 & $74-84$ & 0.6662 & $46.48^{* \star}$ & 1.0000 & 0.7103 & -0.4078 \\
\hline OarCP34 & 5 & 4.2237 & $112-128$ & 0.7253 & $21.70^{\mathrm{NS}}$ & 0.6596 & 0.7632 & 0.1358 \\
\hline OarFCB128 & 5 & 4.2747 & $112-120$ & 0.7266 & $83.04^{\star *}$ & 0.2609 & 0.7661 & 0.6595 \\
\hline OarFCB20 & 6 & 4.3229 & $92-116$ & 0.7317 & $24.45^{\mathrm{NS}}$ & 0.5745 & 0.7687 & 0.2527 \\
\hline OarFCB48 & 5 & 4.1624 & $144-160$ & 0.7196 & $47.21^{* *}$ & 0.4667 & 0.7598 & 0.3858 \\
\hline OarHH35 & 6 & 4.4022 & $118-138$ & 0.7394 & $142.33^{* *}$ & 0.2000 & 0.7728 & 0.7142 \\
\hline OarHH41 & 8 & 4.8340 & $120-150$ & 0.7628 & $269.10^{* *}$ & 0.6364 & 0.7931 & 0.1977 \\
\hline OarHH47 & 2 & 1.9406 & $62-64$ & 0.3712 & $7.95^{*}$ & 0.2750 & 0.4847 & 0.4326 \\
\hline OarHH64 & 5 & 3.5237 & $118-136$ & 0.6780 & $35.28^{* *}$ & 0.6087 & 0.7162 & 0.1501 \\
\hline OarJMP29 & 7 & 5.1601 & $124-148$ & 0.7776 & $46.62^{*}$ & 0.8750 & 0.8062 & -0.0853 \\
\hline OarJMP8 & 5 & 3.3508 & $110-134$ & 0.6496 & $56.68^{\star *}$ & 0.3043 & 0.7016 & 0.5662 \\
\hline OarVH72 & 5 & 3.9293 & 124-134 & 0.6817 & $41.41^{* *}$ & 0.6316 & 0.7455 & 0.1528 \\
\hline RM004 & 6 & 3.8535 & $138-148$ & 0.7013 & $62.75^{\star \star}$ & 0.4000 & 0.7405 & 0.4598 \\
\hline TGLA137 & 6 & 5.3928 & $138-156$ & 0.7872 & $92.69^{* \star}$ & 0.6000 & 0.8146 & 0.2634 \\
\hline TGLA377 & 6 & 2.3655 & $76-100$ & 0.5347 & $37.58^{*}$ & 0.5417 & 0.5773 & 0.2060 \\
\hline Mean & 5.88 & 4.0950 & $62-230$ & 0.6905 & -- & 0.5202 & 0.7339 & 0.2954 \\
\hline & \pm 0.29 & \pm 0.23 & & \pm 0.0212 & & \pm 0.227 & \pm 0.087 & \pm 0.309 \\
\hline
\end{tabular}

for Vembur was comparable with that of Nilagiri but lower than both Madras Red and Mecheri. The deficiency of heterozygotes in the population may be due to selective breeding over the generations.

Within-population inbreeding estimate $\left(F_{I S}\right)$

FIS values were negative for three loci OarCP20 and OarJMP29) the presence of more heterozygotes at the loci. The remaining loci revealed FIS values ranging from 0.1005 in BM1314 to 0.7882 in BM8125, indicating presence of inbreeding of varying degrees. The mean $F_{I S}$ value observed was $0.2954 \pm 0.31$ (Table 1) indicating the homozygous/inbree ding status of the population. $\quad F_{I S}$ estimates reported in most of the

Departure from HWE was also reported in Jalauni breed (Arora et al., 2008), Pag Island sheep breed (Ivankovic et al., 2005), Turkish sheep breeds (Soysal et al., 2005), West African Djallonke breed (Wafula et al., 2005), sheep breeds of Northern Spain (Alvarez et al., 2004), loci Baltic sheep breeds (Grigaliunaite et al., 2003), Sasi sheep (Rendo et al., 2003), and Uruguayan Corriedale (Tomasco et al., 2002).

Estimation of observed and expected heterozygosity

The observed heterozygosity ( $\mathrm{Ho})$ values varied between 0.1333 (BM1314) to 1.000 (OarCP20), while the expected values $(\mathrm{He})$ ranged from $0.4847(\mathrm{OarHH} 47)$ to 0.8537 (HUJ616). The mean values were $0.5202 \pm 0.04$ and $0.7339 \pm 0.02$ for $\mathrm{Ho}$ and $\mathrm{He}$ respectively (Table 1). When viewed in relation with figures for Tamilnadu breeds, the observed heterozygosity of 0.52 in Vembur sheep was lower than that for Nilagiri (Girish et al., 2007), Madras Red and Mecheri (Prema et al., 2008; Selvam et al., 2009). The expected heterozygosity value of 0.7339 literature indicated various levels of inbreeding as 0.19 in Sarda sheep (Pariset et al., 2003), 0.066 in Spanish breeds (Alvarez et al., 2004), and 0.033 in Turkish sheep breeds (Soysal et al., 2005). Among the Indian sheep breeds, Arora and Bhatia (2004) reported a mean FIS value of 0.058 in Muzzafarnagri indicating a very low rate of inbreeding in that population. However, a high rate of inbreeding was reported in Nali and Chokla (0.397 and 0.299 respectively; Sodhi et al., 2005) and Magra (0.159; Arora \& Bhatia, 2006) sheep breeds.

\section{Conclusion}

The genetic analysis of Vembur sheep returned several clues on the genetic status of its present population. The breed had allelic diversity, which indicates genetic variation. The mean PIC value of 0.69 justified the selection of markers for the study. The departure from HWE in majority of the loci can be attributed to shrinkage in population size and selection process which had been progressing in the population. Ex
Research article

CIndian Society for Education and Environment (iSee)
"Vembur sheep: molecular characterization" http://www.indjst.org
Pramod et al. Indian J.Sci.Technol. 
situ and In situ conservation of the breed are the best options suggested and the need of the hour for conservation of this breed.

\section{Acknowledgement}

The authors express sincere gratitude to the Director, NBAGR, Dr.Gurmej Singh, Principal Scientist I/c Network Projects, Dr.B.P.Mishra, Co-ordinator, Network ProjectsCore Laboratory, National Bureau of Animal Genetic Resources, Karnal for the Administrative and financial support by ICAR, New Delhi, through ICAR Network Projects - Core Laboratory. We thank Tamilnadu Veterinary and Animal Sciences University for providing facilities to this study.

\section{References}

1. Acharya RM (1982) Sheep and Goat breeds of India. FAO Animal Production and Health Paper 30.

2. Alvarez I, Royo LJ, Fernandez I, Gutierrez JP, Gomez E and Goyache F (2004) Genetic relationships and admixture among sheep breeds from northern Spain assessed using microsatellites. J. Animal Sci. 82(8), 2246-2252.

3. Arora R and Bhatia S (2004) Genetic structure of Muzzafarnagri sheep based on microsatellite analysis. Small Ruminant Res. 54, 227-230.

4. Arora R and Bhatia S (2006) Genetic diversity of Magra sheep from India using microsatellite analysis. AsianAus. J. Anim. Sci. 19, 938-942.

5. Arora R, Bhatia S, Sehrawat A, Maity SB and Kundu SS (2008) Genetic variability in Jalauni sheep of India inferred from microsatellite data. Article no. 4 retrieved from www.cipav.org.co/lrrrd20/1/ aror20004.htm on 2/5/2008.

6. Botstein D, White RL, Skolnick M, and Davis RW (1980) Construction of a genetic linkage map in man using restriction fragment length polymorphisms. Am J. Hum. Genet. 32, 314-331.

7. FAO (2004) Secondary guidelines for development of national farm animal genetic resources management plans for global management of cattle genetic resources using reference microsatellites global projects for the maintenance of domestic animal genetic diversity (MoDAD). [http://www.fao.org/dad-is/]

8. Ganesakale D and Rathnasabapathy V (1973) Sheep breeds of Tamil Nadu. Cheiron. 2 (2), 146-155.

9. Girish H, Sivaselvam SN, Karthikeyan SMK and Saravanan R (2007) Molecular characterisation of Nilagiri sheep (Ovis aries) of south India based on microsatellites. Asian-Aust. J. Anim. Sci. 20(5), 633-637.

10. Grigaliunaite I, Tapio M, Viinalass $\mathrm{H}$, Grislis Z, Kantanen $J$ and Miceikiene I (2003) Microsatellite variation in the Baltic sheep breeds. Veterinarija ir zootechnika T. 21 (43), 66-73.

11. Gutierez-Espelelata G, Kalinowski ST, Boyce WM and Hedrick PW (2000) Genetic variation and population structure in desert bighorn sheep: implications for conservation. Conserv. Genet. 1, 3-15.

12. Ivankovic AP, Dove $P$, Kavar $P$, Caput $P$, Mioe B, Pavie $V$, Stuhee V and Leto J (2005) Genetic characterisation of the Pag Island sheep breed based on microsatellite and mtDNA data. Small Ruminant Res. 57, 167-174.

13. Kumarasamy P, Prema S, Ganapathi P, Karthikeyan, SMK and Kanakaraj P (2009) Molecular characterization of Coimbatore breed of sheep (Ovis aries) in South India. The IUP J. Genet. \& Evol. 2 (3), 56-65.

14. Lujiang $\mathrm{Qu}$, Xianyao $\mathrm{Li}$, Guiquin Wu and Ning Yang (2005) Efficient and sensitive method of DNA silver staining in polyacrylamide gels. Electrophoresis. 26, 99101.

15. Peters J, Helmer D, Von den Driesch A and Segui $S$ (1999) Animal husbandry in the northern Levant. Paléorient. 25, 27-48.

16. Prema S, Sivaselvam SN and Karthickeyan SMK (2008) A note on genetic analysis in Madras Red sheep (Ovis aries) of India using microsatellite markers. Livestock Res. for Rural Develop. 20 (11), paper 181.

17. Rendo $F$, Iriondo I, Jugo BM, Mazon LI, Aguirre A, Vicario A and Estonba E (2003) Tracking diversity and differentiation in six sheep breeds from the North Iberian Peninsula through DNA variation. Small Ruminant Res. 52, 195-202.

18. Sambrook J, Fritsch EF and Maniatis T (1989) Molecular cloning: a laboratory manual, Cold Spring Harbour Lab. press, Cold Spring Harbour, USA.

19. Selvam R, Rahumathulla PS, Sivaselvam SN, Karthickeyan SMK and Rajendran R (2009) Molecular genetic characterization of Madras Red sheep in Tamil Nadu, India using microsatellite markers. Livestock Res. for Rural Develop. 21 (4) paper 50.

20. Shrestha JNB (2005) Conserving domestic animal diversity among composite populations. Small Ruminant Res. 56, 3-20.

21. Sodhi M, Mukesh M and Bhatia S (2005) Characterising Nali and Chokla sheep differentiation with microsatellite markers. Small Ruminant Res. 65(3), 185-92.

22. Sodhi M, Mukesh M, Arora R, Tantia MS and Bhatia S (2003) Genetic structure of Garole-a unique Indian microsheep assessed using microsatellite markers. Indian J. Dairy Sci. 56, 167-173.

23. Soysal MI, Koban E, Ozkan E, Altunok V, Bulut Z, Nizamlioglu M and Togan I (2005) Evolutionary relationship among three native and two crossbreed sheep breeds of Turkey: preliminary results. Revue de Medecine Veterinaire. 156, 289-293.

24. Tomasco I, Wlasiuk G and Lessa EP (2002) Evaluation of polymorphism in ten microsatellite loci in Uruguayan sheep flocks. Gen. Mol. Biol. 25(1), 37-41.

25. Wafula $P O$, Jianlin $H$ Sangare $H$, Sowe JM, Coly $R$, Diallo B and Hanotte O (2005) Genetic characterisation of West African Djallonke sheep using microsatellite markers. The Role of Biotechnol. 5- 7, 177-178.

26. Yeh FC, Boyle T, Rongcai Y, Ye Z and Xian JM (1999) Popgene, Version 1.31. A Microsoft Windows based freeware for population genetic analysis. University of Alberta, Edmonton.
Research article

CIndian Society for Education and Environment (iSee)
"Vembur sheep: molecular characterization" http://www.indjst.org
Pramod et al. Indian J.Sci.Technol. 